\title{
Caracterización clínica-epidemiológica de pacientes con coinfección tuberculosis pulmonar-VIH del hospital José Rodríguez 2015-2016
}

\section{Clinical-epidemiological characterization of pulmonary tuberculosis-VIH co-infection patients at José Rodríguez hospital 2015-2016}

\author{
Alex Alberto Castillo Zhizhpón ${ }^{1 *}$, Sara Elizabeth Bravo Salinas ${ }^{2}$ \\ ${ }^{1}$ Instituto Ecuatoriano de Seguridad Social \\ ${ }^{2}$ Universidad Católica de Cuenca \\ *acz8@hotmail.com
}

DOI: https://doi.org/10.26871/killkana_salud.v4i1.580

\begin{abstract}
Resumen
Contexto: La tuberculosis es una infección bacteriana causada por el Mycobacterium tuberculosis, es la primera enfermedad oportunista en los pacientes VIH-positivos. Objetivo: Caracterizar clínica y epidemiológicamente a los pacientes que presentan coinfección VIH-Tuberculosis pulmonar, del hospital José Rodríguez Maridueña entre enero de 2015 a diciembre de 2016. Metodología: Estudio descriptivo, transversal, retrospectivo basado en el análisis de las historias clínicas de pacientes con diagnóstico de ingreso de tuberculosis pulmonar y VIH, del hospital José Rodríguez Maridueña entre enero del 2015 a diciembre del 2016. Resultados: La tasa de coinfección fue 44,9\%;(IC $95 \%$ 37,12-52,69) el análisis conjunto de las variables demostró que estas personas son mayores a 37 años (OR ajustada 3,45; $\mathrm{IC}_{95} \%$ 1,378,68), con primaria (OR ajustada 2,67; $\mathrm{IC}_{95} \%$ 1,20-6,28), diagnosticados por otros métodos (OR ajustada 3,23; $\mathrm{IC}_{95} \%$ 1,35-7,76), carga viral menor a 175318 copias de ARN/mL (OR ajustada 4,73; $\mathrm{IC}_{95} \%$ 1,77-12,6), CD4 menor a 140 (OR ajustada 2,94; IC $_{95} \%$ 1,18-7,29), no toman TARGA (OR 3,00; IC $_{95} \%$ 2,36-3,80). Conclusiones: El perfil de riesgo en esta coinfección es tener 37 años o más, educación primaria, diagnosticada por métodos distintos a baciloscopía, carga viral menor a 175318 copias de ARN/mL, conteo de linfocitos TCD4+ menor a 140 cél/mm³ , no tomar TARGA (100\%).
\end{abstract}

Palabras clave: carga viral, drogas, VIH, SIDA, Tuberculosis pulmonar.

\begin{abstract}
Context: Tuberculosis is a bacterial infection caused by Mycobacterium tuberculosis; it is the first opportunistic disease in HIV-positive patients. Objective: To clinically and epidemiologically characterize patients presenting HIVPulmonary tuberculosis co-infection, at José Rodríguez Maridueña Hospital, between January 2015 and December 2016. Methodology: This is a descriptive, cross-sectional, and retrospective study based on the analysis of the clinical records of diagnosed pulmonary tuberculosis and HIV patients at José Rodríguez Maridueña Hospital, between January 2015 and December 2016. Results: The coinfection rate was $44.9 \%$ (IC $95 \%$ 37.12-52.69). The pooled analysis of the variables revealed that these people were older than 37 years (adjusted $O R$ 3.45; IC $95 \%$ 1.37-8.68), they had primary education (adjusted OR 2.67; IC $C_{95 \%}$ CI 1.20-6.28) were diagnosed by other methods (adjusted OR 3.23; IC $95 \%$ CI 1.35-7.76). Their viral load was less than 175318 copies RNA/mL (adjusted OR 4.73; IC ${ }_{95 \%}$ CI 1.77-12.6), CD4 less than 140 (adjusted OR

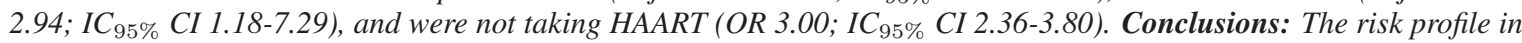
this co-infection is to be 37 years or older, with primary education; to be diagnosed by methods other than bacilloscopy, to have a viral load smaller than 175318 copies $R N A / m L$, with a TCD4+ lymphocyte count less than 140 cells $/ \mathrm{mm}^{3}$, and not to be taking HAART (100\%).
\end{abstract}

Keywords: viral load, drugs, HIV, AIDS, pulmonary tuberculosis. 


\section{Introducción}

La tuberculosis (TB) es una importante enfermedad infecciosa ya que repercute no solo en la persona que la padece sino en su entorno. Las desigualdades socioeconómicas presentes en las diversas poblaciones, la demora en la detección, el inadecuado tratamiento, los cambios demográficos, la infección con el virus de inmunodeficiencia humana (VIH) son factores que contribuyen a que se siga desarrollando. ${ }^{1}$

Las poblaciones fronterizas tienen especificidades socioculturales que la diferencian del resto del país al que pertenecen, como la circulación de población en ambos sentidos de la frontera, inadecuado acceso a los servicios de salud, deficiente calidad de atención en salud, tráfico de armas y drogas, prostitución, propagación de infecciones de transmisión sexual como el VIH/SIDA, hacinamiento, pobreza, características que dan como resultado la propagación de enfermedades transmisibles. ${ }^{2}$

Los factores atribuibles para presentar tuberculosis en el futuro son estado inmune del individuo, diabetes, VIH, alcoholismo, desnutrición, tabaquismo, contaminación interna del aire, estando los de nivel socioeconómico bajo más expuestos a estos factores de riesgo, y por lo tanto siendo vulnerables a exposición a bacilo de Koch, ser contacto de personas con tuberculosis, hacinamiento. ${ }^{3}$

Los pacientes con tuberculosis bacilífera no diagnosticada oportunamente transmiten la enfermedad por las gotas de saliva, siendo los migrantes, adultos mayores, personas en hacinamiento, inmunodeprimidos, los más afectados. ${ }^{4}$

Los factores que aumentan el riesgo de transmisión nosocomial son retardo en el diagnóstico, inadecuada infraestructura para el aislamiento de los casos, demora en el inicio del tratamiento, fallas en la utilización de la protección respiratoria. $^{5}$

En el 2012 se estimó que 8,6 millones de personas desarrollaron la enfermedad, de las cuales 2,9 millones eran mujeres, 1,1 millones fueron VIH positivos, 450000 personas fueron multidrogorresistentes-tuberculosis (MDR-TB). ${ }^{6}$

Ecuador para el año 2014 los casos incidentes de VIH/TB es de 1200 correspondiendo al 3,3\% del total de casos reportados en las Américas. ${ }^{7}$

En un estudio realizado entre 2001 y 2003 la prevalencia de la TB en comunidades de la región central de la Sierra Ecuatoriana fue de 6700 casos por 100000 habitantes, ${ }^{8}$ una de las tasas de prevalencia más altas de las que se registra en la literatura científica.

El número de casos de tuberculosis notificados para el 2012 fue de 5.456, la tasa de detección de casos de todas las formas de TB fue $60 \%$ para este mismo año, la tasa de éxito terapéutico en la tuberculosis con frotis positivo para el año 2011 fue del $68 \%$, la tasa de mortalidad por tuberculosis en personas seronegativas para VIH fue del 2,7 por 100000 habitantes para el 2012. ${ }^{9}$

La tuberculosis es una enfermedad concentrada en el Ecuador, con 3373 casos nuevos esputo positivo en el 2010, de los cuales 2156 fueron hombres, 114 resistentes a múltiples drogas, el grupo etario más afectado fue de 15 a 34 años. ${ }^{10}$

El costo de la tuberculosis para los pacientes y sus familias en el Ecuador son altos y en el caso de MDR-TB es aún más elevado, con un promedio por paciente de 960 dólares americanos para no MDR-TB y de 6880 dólares americanos para MDR-TB. ${ }^{11}$

Mediante encuestas realizadas en países de bajos y medianos ingresos se reportó que los costos de la tuberculosis para gastos médicos directos fueron del $20 \%$, gastos no médicos directos $20 \%$ y gastos indirectos (disminución de ingresos) $60 \% .^{12}$

La infección por el HIV hoy en día considerada uno de los principales factores de riesgo para adquirir tuberculosis pulmonar (TBP) a partir de una infección latente por bacilo de koch. ${ }^{13}$

Un estudio realizado en 74 personas coinfectadas con tuberculosis-VIH 79,7\% eran hombres, la edad predominante estaba comprendida de 30 a 39 años, en cuando al estado civil el $31,1 \%$ correspondían a personas casadas, el $42,4 \%$ cursaron estudios superiores. ${ }^{13}$

Un tercio de los 38,6 millones de personas que están infectada por VIH en el mundo presenta infección latente por Mycobacterium tuberculosis, corriendo un riesgo mayor de padecer tuberculosis activa. ${ }^{14}$

En las Américas se notificaron 21978 casos de tuberculosis/VIH, casi el $50 \%$ de los casos en Haití y Brasil, de los 39 países solo 14 reportan datos sobre tratamiento para infección latente de tuberculosos en personas con VIH. ${ }^{7}$

La tuberculosis pulmonar en pacientes con VIH o en estados de inmunosupresión, se caracteriza por manifestaciones clínicas atípicas, en estados avanzados de VIH las manifestaciones radiográficas pueden no estar presentes, hasta un $22 \%$ de personas con VIH y TB pueden tener una radiografía normal. ${ }^{15}$

La baciloscopía registra un costo promedio de 2,41 dólares por prueba, con una sensibilidad del $86 \%$ y una especificidad del $97 \%$ para países con alta prevalencia de tuberculosis. ${ }^{16}$ La sensibilidad de la baciloscopía se compromete cuando la carga de bacilos causantes de la tuberculosis es menos de 10.000 organismos por mililitro de muestra de esputo. ${ }^{17}$

Los pacientes con estado avanzado de inmunosupresión tienen a menudo tuberculosis paucibacilar que a menudo disminuye la sensibilidad de la baciloscopía, siendo necesario para su diagnóstico pruebas como el cultivo de esputo. ${ }^{18}$

El informe mundial de TB 2015 señala que la mortalidad de tuberculosis corresponde a 21 por 100000 habitantes en pacientes VIH positivos según Torres del Águila, 2016.

La tuberculosis es la principal causa de muerte por enfermedades infecciosas en personas que viven con VIH, las personas con VIH tienen mayor riesgo de reactivación de una tuberculosis latente, así como una respuesta inmunológica deficiente, el uso adecuado de los antiretrovirales disminuye en un $65 \%$ el riesgo de desarrollar tuberculosis, independiente del conteo de linfocitos CD $4 .{ }^{13}$ 
El programa de control de tuberculosis consiste en un ciclo de seis a ocho meses con el uso de 4 a 5 potentes antituberculosos como son: isoniacida, rifampicina, etambutol, pirazinamida y estreptomicina. ${ }^{19}$

La terapia antiretroviral es la intervención más importante para reducir la mortalidad en pacientes con tuberculosis VIH positivos, además del inicio oportuno de la terapia antiretroviral la principal intervención para prevenir TB en pacientes con VIH es la terapia preventiva con isoniazida. ${ }^{18}$

En coinfección VIH-Tuberculosis la adhesión inadecuada al tratamiento antituberculoso es mayor en hombres $(78,1)$, solteros $(61 \%)$, desempleados $(47 \%)$ y $76,5 \%$ de las personas con un ingreso inferior al salario mínimo. ${ }^{13}$

El ingreso al tratamiento para tuberculosis multidrogorresistente tiene como causa principal el fracaso terapéutico mismo o abandono, ser contacto de pacientes con TBMDR, ser nuevos en el tratamiento. El antecedente de haber tenido tuberculosis incrementa 28 veces el riesgo de TBMDR, el riesgo se incrementa 1,7 veces al tener un familiar con TB-MDR y el antecedente de un familiar fallecido por tuberculosis incrementa 4 veces el riesgo de la misma, el tener VIH, estar en bajo peso acorde al índice de masa corporal incrementa el riesgo de TB-MDR 7,5 y 5 veces más respectivamente dicho riesgo. ${ }^{20}$

\section{Metodología}

Estudio descriptivo transversal, retrospectivo mediante el análisis de las historias clínicas de los pacientes VIHpositivos hospitalizados entre 2015 - 2016, diagnosticados presuntivamente de tuberculosis pulmonar en el Hospital de Infectología Dr. José Daniel Rodríguez Maridueña, ubicado en la ciudad de Guayaquil-Ecuador.

\subsection{Población de estudio}

La población que formó parte del estudio; corresponde a pacientes con infección por VIH o sida que por demanda espontanea acudieron a el área de consulta externa o emergencia del Hospital José Daniel Rodríguez Maridueña y que presentaron diagnóstico presuntivo de tuberculosis pulmonar a los cuales mediante exámenes de laboratorio se llegó a confirmar o descartar dicho diagnóstico, durante el periodo comprendido entre 01 de enero del 2015 al 31 de diciembre del 2016.

De esta manera se pudo analizar un total de 167 historias clínicas, de los cuales 75 pacientes tuvieron diagnóstico definitivo de coinfección VIH/TBP, y en 92 pacientes se descartó dicho diagnóstico mediante la negativización para TB de los exámenes complementarios, los cuales revelaron otras patologías.

\subsection{Criterios de inclusión}

Los criterios de inclusión para el estudio son:

1) Pacientes con diagnóstico presuntivo de coinfección VIH-TBP por clínica.
2) Disponibilidad de la historia clínica y disponibilidad de resultados de exámenes complementarios en las historias clínicas

3) Egresados del Hospital José Daniel Rodríguez Maridueña del 01 de enero del 2015 al 31 de diciembre del 2016.

El presente estudio se desarrolló bajo la aprobación del campus Esther y revisión del tutor, el análisis de los datos se realizó de febrero a marzo del 2018; previa autorización del Director Técnico y del Jefe de Docencia del Hospital.

Para el análisis de las variables se calculó la media de la población en estudio, o se tomó la variable más frecuente de la población en estudio, y mediante ello se re-categorizó las variables originales.

\subsection{Análisis Estadístico}

De la base de datos se realizó descriptivas bivariante, se recategorizaron variables en este caso edad, residencia, educación, ocupación, método diagnóstico, carga viral, linfocitos T CD4, estancia hospitalaria que se convirtieron en variables dicotómicas.

El análisis de las relaciones entre variables categóricas se efectuó mediante el contraste de independencia a través de la razón de verosimilitudes y se consideró el valor $\mathrm{p}$ $<0,05$. La fuerza de asociación se realizó mediante cálculo de Razón de prevalencias (RP) y Razón de Ventajas (OR), $\mathrm{IC}_{95 \%}$. Se realizó la descriptiva multivariante mediante regresión logística para la generación de grupos de riesgo.

\section{Resultados}

De los 167 pacientes VIH positivos con diagnóstico presuntivo de TBP se identificaron 75 (44,9\%; IC $95 \% 37,12$ $52,69)$ personas que fueron confirmadas de TBP mediante exámenes de laboratorio y de los cuales se detallará sus características.

\subsection{Características de coinfección VIH/TB pulmonar es- tratificado por edad y sexo}

Dentro de los 50 participantes del total que tiene 37 años o más; 32 (64\%; IC $_{95 \%}$ 50-76) tuvieron coinfección VIH/TB Pulmonar, de los 117 participantes del total de menores de 37 años; 43 (36,8\%; IC $95 \%$ 28,20-45,29) tuvo dicho antecedente, la relación entre estas dos variables demostró que existe $74 \%$ (RP 1,74; $\mathrm{IC}_{95} \%$ 1,27-2,38) más probabilidad de tener coinfección VIH/TBP al tener 37 años o más en relación a ser menor 37 años.

En cuanto al sexo, del total de participantes; 119 son hombres, de los cuales 57 (47,9\%; IC $_{95 \%}$ 37,81-56,30) tuvieron antecedente de coinfección, de las 48 mujeres del total de población, 18 (37,5\%; IC $_{95 \%}$ 25-52,08) tuvieron dicho antecedente, la probabilidad tener coinfección fue $27 \%$ más al ser hombre (RP 1,27; $\mathrm{IC}_{95 \%}$ 0,84-1,92), como se muestra en la tabla 1 
Tabla 1. Característica de coinfección VIH/TBP estratificado por edad y sexo

\begin{tabular}{|c|c|c|c|c|c|c|c|}
\hline Variable & Categoría & $\mathrm{N}$ & $\%^{a}$ & Total & $\mathrm{IC}_{95 \%}$ & $\mathrm{RP}$ & $\mathrm{IC}_{95 \%}$ \\
\hline \multirow{3}{*}{ Edad } & & & & & & 1,74 & $1,27-2,38$ \\
\hline & Menor de 37 & 43 & 36,8 & 117 & $28,20-45,29$ & & \\
\hline & 37 años o más & 32 & 64 & 50 & $50-76$ & & \\
\hline \multirow{3}{*}{ Sexo } & & & & & & 1,27 & $0,84-1,92$ \\
\hline & Hombre & 57 & 47,9 & 119 & $37,81-56,30$ & & \\
\hline & Mujer & 18 & 37,5 & 48 & $25-52,08$ & & \\
\hline
\end{tabular}

${ }^{a}$ El porcentaje del denominador corresponde a la variable de la fila

n Tamaño de muestra

$\mathrm{IC}_{95 \%}$ Intervalo de confianza del $95 \%$

RP Razón de prevalencias

Fuente: Estudio "Caracterización clínica-epidemiológica de pacientes con coinfección Tuberculosis pulmonar-VIH del Hospital José Rodríguez 2015 $2016 "$

Elaborado por: Castillo A.

3.2 Características de coinfección VIH/TB pulmonar estratificado por residencia, ocupación, educación

Dentro de los 134 participantes que son de Guayaquil 61 (45,5\%; IC $_{95 \%}$ 37,31-53,73) tuvieron coinfección, de la población de otras Provincias 14 (42,4\%; $\mathrm{IC}_{95 \%}$ 27,27$60,60)$ tuvo dicho Diagnostico, la probabilidad tener coinfección fue $7 \%$ (RP 1,07; $\mathrm{IC}_{95} \%$ 0,69-1,66) mayor al ser de Guayaquil en relación al ser de otra provincia, como se puede ver en la tabla 2.

Tabla 2. Características de coinfección VIH/TBP estratificado por residencia, ocupación, educación

\begin{tabular}{|c|c|c|c|c|c|c|c|}
\hline Variable & Categoría & $\mathrm{N}$ & $\%^{a}$ & Total & $\mathrm{IC}_{95 \%}$ & $\mathrm{RP}$ & $\mathrm{IC}_{95 \%}$ \\
\hline \multirow[b]{2}{*}{ Residencia } & & & & & & 1,07 & $0,69-1,66$ \\
\hline & Guayaquil & 61 & 45,5 & 134 & $37,31-53,73$ & & \\
\hline \multirow[b]{2}{*}{ Ocupación } & & & & & & 1,40 & $0,96-2,05$ \\
\hline & Empleado & 52 & 50,5 & 103 & $40,77-60.19$ & & \\
\hline \multirow[t]{2}{*}{ Educación } & Primaria & 49 & 56,3 & 87 & $45,97-66,66$ & & \\
\hline & Otros & 26 & 32,5 & 80 & $22,5-42,5$ & & \\
\hline
\end{tabular}

${ }^{a}$ El porcentaje del denominador corresponde a la variable de la fila n Tamaño de muestra

$\mathrm{IC}_{95} \%$ Intervalo de confianza del $95 \%$

RP Razón de prevalencias

Fuente: Estudio "Caracterización clínica-epidemiológica de pacientes con coinfección Tuberculosis pulmonar-VIH del Hospital José Rodríguez 2015 - 2016" Elaborado por: Castillo A.

En cuanto a la ocupación, de los 103 pacientes con empleo; 52 (50,5\%; $\mathrm{IC}_{95 \%}$ 40,77-60,19) tuvieron coinfección, de los pacientes sin empleo, 23 (35,9\%; IC $95 \% 25$ $48,43)$ tuvieron dicho antecedente, la probabilidad tener coinfección fue $40 \%$ más al tener algún tipo de empleo (RP 1,$40 ; \mathrm{IC}_{95 \%}$ 0,96-2,05), como se muestra en el cuadro 3.

Dentro de educación, de los 87 pacientes con Primaria; 49 (56,3\%; $\mathrm{IC}_{95 \%}$ 45,97-66,66) tuvieron coinfección, de los pacientes con otros niveles de instrucción 26 (32,5\%; $\mathrm{IC}_{95 \%}$ 22,5-42,5) tuvieron dicho diagnóstico, la probabilidad tener coinfección fue $73 \%$ más al tener como estudios primaria ( $\left.\mathrm{RP} 1,73 ; \mathrm{IC}_{95} \% 1,20-2,49\right)$, como se muestra en la tabla 2
3.3 Características de coinfección VIH/TBP estratificado por método diagnóstico, carga viral, linfocitos TCD4+

Dentro de los 61 participantes a los que se les realizo otros métodos diagnósticos, 36 (59\%; IC $_{95 \%}$ 45,90-70,49) tuvieron coinfección diagnosticada por métodos distintos a la baciloscopía, mientras que 39 (36,8 \%; $\mathrm{IC}_{95 \%}$ 27,3546,22 ) tuvo coinfección VIH/TBP diagnosticada por baciloscopía, en el cuadro 3 se muestra la relación entre estas dos variables donde se demostró que existe $60 \%$ (RP 1,60; $\mathrm{IC}_{95 \%}$ 1,15-2,22) más posibilidad de ser diagnosticado de coinfección VIH/TBP por métodos distintos a la baciloscopía. 
Tabla 3. Características de coinfección VIH/TBP estratificado por método diagnóstico, carga viral, linfocitos TCD4+

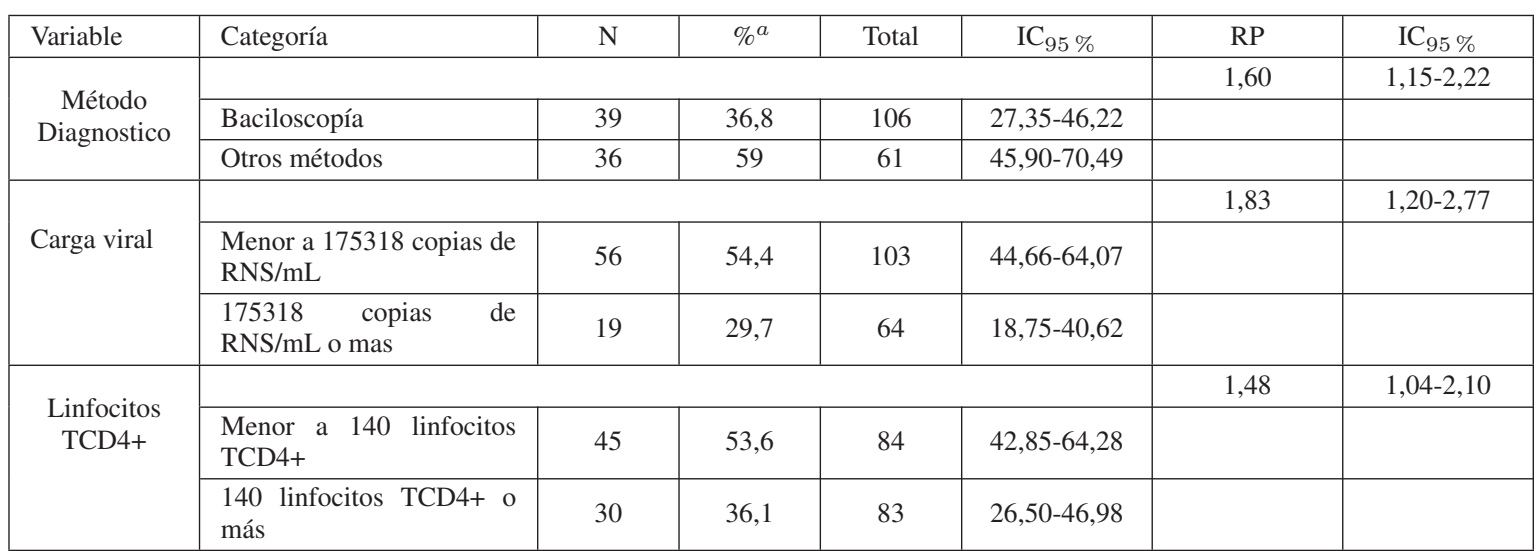

${ }^{a}$ El porcentaje del denominador corresponde a la variable de la fila n Tamaño de muestra

$\mathrm{IC}_{95} \%$ Intervalo de confianza del $95 \%$

RP Razón de prevalencias

Fuente: Estudio “Caracterización clínica-epidemiológica de pacientes con coinfección Tuberculosis pulmonar-VIH del Hospital José Rodríguez 2015 2016"

Elaborado por: Castillo A

En cuanto a la carga viral, de los 103 pacientes con $\mathrm{CV}$ menor a 175318 copias de $\mathrm{ARN} / \mathrm{ml} ; 56\left(54,4 \% ; \mathrm{IC}_{95} \%\right.$ 44,66-64,07) tuvieron coinfección, de los pacientes con carga viral de 175318 copias de RNA/ml o más, 19 (29,7\%; $\mathrm{IC}_{95 \%}$ 18,75-40,62) tuvieron dicho antecedente, la probabilidad tener coinfección fue $83 \%$ más al tener carga viral menor a 175318 copias de RNS/ml (RP 1,83; IC $95 \%$ 1,202,77), como se muestra en la tabla 3.

En cuanto a los linfocitos TCD4+, de los 84 pacientes con linfocitos TCD4+ menor a 140; $45\left(53,6 \%\right.$; $\mathrm{IC}_{95 \%}$ 42,85-64,28) tuvieron coinfección, de los pacientes con linfocitos TCD4+ de 140 o más, 30 (36,1 \%; IC $_{95 \%}$ 26,50$46,98)$ tuvieron dicho diagnóstico, la probabilidad de tener coinfección fue $48 \%$ más al tener linfocitos TCD4+ menor a 140 (RP 1,48; $\mathrm{IC}_{95 \%}$ 1,04-2,10).

\subsection{Características de coinfección VIH/TBP estratificado por días de estancia hospitalaria, antecedente de tratamiento}

En cuanto a estancia hospitalaria, de los 94 pacientes con una estancia menor a 10 días; 47 (50\%; IC $_{95 \%}$ $40,42-59,57)$ tuvieron coinfección, de los pacientes con una estancia de 10 días o más, 28 (38,4\%; IC $_{95 \%} \%$ 27,39$49,31)$ tuvieron dicho antecedente, la probabilidad de tener coinfección fue $30 \%$ más al tener una estancia hospitalaria menor a 10 días (RP 1,30; $\mathrm{IC}_{95 \%}$ 0,91-1,85), como se muestra en la tabla 4.

Tabla 4. Característica de coinfección VIH/TB pulmonar estratificado por edad y sexo

\begin{tabular}{|c|c|c|c|c|c|c|c|}
\hline Variable & Categoría & $\mathrm{N}$ & $\%^{a}$ & Total & $\mathrm{IC}_{95 \%}$ & $\mathrm{RP}$ & $\mathrm{IC}_{95 \%}$ \\
\hline \multirow{2}{*}{$\begin{array}{c}\text { Días de } \\
\text { estancia } \\
\text { hospitalaria }\end{array}$} & & & & & & 1,30 & $0,91-1,85$ \\
\hline & Menor a 10 días & 47 & 50 & 94 & $40,42-59,57$ & & \\
\hline \multirow{2}{*}{$\begin{array}{c}\text { Antecedente } \\
\text { de } \\
\text { tratamiento }\end{array}$} & & & & & & 3,00 & $2,36-3,80$ \\
\hline & $\mathrm{Si}$ & 46 & 33,3 & 138 & $25,36-41,30$ & & \\
\hline
\end{tabular}

${ }^{a}$ El porcentaje del denominador corresponde a la variable de la fila

n Tamaño de muestra

$\mathrm{IC}_{95} \%$ Intervalo de confianza del $95 \%$

RP Razón de prevalencias

Fuente: Estudio "Caracterización clínica-epidemiológica de pacientes con coinfección Tuberculosis pulmonar-VIH del Hospital José Rodríguez 2015 2016"

Elaborado por: Castillo A.

Dentro de antecedente de tratamiento, de los 29 pacientes que no tomaban TARGA; 29 (100\%) tuvieron coinfección, de los pacientes con TARGA, 46 (33,3\%; IC $95 \%$
25,36-41,30) tuvieron dicho diagnóstico, la probabilidad tener coinfección fue 3 veces más al no tomar TARGA (RP 3,$00 ; \mathrm{IC}_{95 \%}$ 2,36-3,80), como se muestra en la tabla 4 . 
Perfil de riesgo en personas mayores de 15 años con coinfección VIH-tuberculosis pulmonar, del Hospital José Rodríguez Maridueña entre enero de 2015 a diciembre de 2016

El modelo de regresión logística fue realizado en un bloque que contiene las variables edad, sexo, residencia, educación, ocupación, método de diagnóstico, carga viral, linfocitos TCD4+, días de estancia hospitalaria, antecedente de tratamiento, con el fin de generar el perfil de las personas con coinfección VIH-TBP, del hospital José Rodríguez Maridueña entre enero del 2015 a diciembre del 2016.

Tabla 5. Perfil de las personas mayores de 15 años con coinfección VIH-Tuberculosis pulmonar, del hospital José Rodríguez Maridueña entre enero del 2015 a diciembre del 2016

\begin{tabular}{|c|c|c|c|c|c|c|c|c|}
\hline Variable & $\mathrm{n}$ & $\%^{b}$ & OR cruda & $\mathrm{IC}_{95 \%}$ & $\mathrm{gl}$ & OR ajustada & $\mathrm{IC}_{95 \%}$ & $\mathrm{gl}$ \\
\hline \multicolumn{3}{|l|}{ Sexo } & 1,53 & $0,77-3,04$ & 1 & 1,19 & $0,43-3,27$ & 1 \\
\hline Hombre & 57 & 47,9 & & & & & & \\
\hline Mujer & 18 & 37,5 & & & & & & \\
\hline \multicolumn{3}{|l|}{ Edad } & 3,05 & $1,53-6,09$ & 1 & 3,45 & $1,37-8,68$ & 1 \\
\hline Menor de 37 & 43 & 36,8 & & & & & & \\
\hline 37 años o más & 32 & 64 & & & & & & \\
\hline \multicolumn{3}{|l|}{ Residencia } & 1,13 & $0,52-2,44$ & 1 & 1,79 & $0,59-5,41$ & 1 \\
\hline Guayaquil & 61 & 45,5 & & & & & & \\
\hline Otras Provincias & 14 & 42,4 & & & & & & \\
\hline \multicolumn{3}{|l|}{ Ocupación } & 1,81 & $0,95-3,44$ & 1 & 1,92 & $0,78-4,69$ & 1 \\
\hline Empleado & 52 & 50,5 & & & & & & \\
\hline Desempleado & 23 & 35,9 & & & & & & \\
\hline \multicolumn{3}{|l|}{ Educación } & 2,67 & $1,42-5,03$ & 1 & 2,67 & $1,20-6,28$ & 1 \\
\hline Primaria & 49 & 56,3 & & & & & & \\
\hline Otros & 26 & 32,5 & & & & & & \\
\hline \multicolumn{3}{|c|}{ Método diagnostico } & 2,47 & $1,29-4,71$ & 1 & 3,23 & $1,35-7,76$ & 1 \\
\hline Baciloscopía & 39 & 36,8 & & & & & & \\
\hline Otros métodos & 36 & 59 & & & & & & \\
\hline \multicolumn{3}{|c|}{ Carga Viral-copias de ARN/ml } & 2,82 & $1,45-5,46$ & 1 & 4,73 & $1,77-12,6$ & 1 \\
\hline Menor a 175318 & 56 & 54,4 & & & & & & \\
\hline 175318 o mas & 19 & 29,7 & & & & & & \\
\hline \multicolumn{3}{|c|}{ Linfocitos TCD4+ } & 2,03 & $1,09-3,78$ & 1 & 2,94 & $1,18-7,29$ & 1 \\
\hline Menor a 140 & 45 & 53,6 & & & & & & \\
\hline 140 o mas & 30 & 36,1 & & & & & & \\
\hline \multicolumn{3}{|c|}{ Estancia hospitalaria } & 1,60 & $0,86-2,99$ & 1 & 2,23 & $0,89-5,58$ & 1 \\
\hline Menor a 10 días & 47 & 50 & & & & & & \\
\hline 10 días o mas & 28 & 38,4 & & & & & & \\
\hline \multicolumn{3}{|c|}{ Antecedente de TARGA } & 2,81 & $2,01-3,60$ & 1 & 3,00 & $2,36-3,80$ & 1 \\
\hline si & 46 & 33,3 & & & & & & \\
\hline no & 29 & 100 & & & & & & \\
\hline
\end{tabular}

Categoría de referencia: ser hombre, ser menor de 37 años, haber cursado años superiores a la primaria, diagnóstico mediante baciloscopía, carga viral igual o mayor a 175318, conteo de linfocitos TCD4+ igual o mayor a 14 células $/ \mathrm{mm}^{3}$, estancia hospitalaria menor a 10 días, no consumo adecuado de TARGA.

${ }^{b}$ El porcentaje del denominador corresponde a la variable de la fila n Tamaño de muestra

IC $_{95} \%$ Intervalo de confianza del $95 \%$

RP Razón de prevalencias

Fuente: Estudio "Caracterización clínica-epidemiológica de pacientes con coinfección Tuberculosis pulmonar-VIH del Hospital José Rodríguez 2015 2016"

Elaborado por: Castillo A.

Como se puede ver en la tabla 5 , la edad 37 años o más (OR ajustada 3,45; IC $_{95} \%$ 1,37-8,68), la educación primaria (OR ajustada 2,67; $\mathrm{IC}_{95} \%$ 1,20-6,28), el tener confección VIH/TB Pulmonar diagnosticada por métodos distintos a la baciloscopía (OR ajustada 3,23; $\mathrm{IC}_{95} \%$ 1,357,76), una $\mathrm{CV}$ menor a 175318 copias de $\mathrm{ARN} / \mathrm{ml}$ (OR ajustada 4,$\left.73 ; \mathrm{IC}_{95} \% 1,77-12,6\right)$, un CD4 menor a 140 (OR ajustada 2,94; $\mathrm{IC}_{95 \%}$ 1,18-7,29), el tener VIH y no tomar TARGA (OR 3,00; IC $95 \%$ 2,36-3,80), explicaron de manera significativa la variabilidad en la probabilidad de presentar antecedente de confección. Si bien entre los hombres, vivir en Guayaquil, tener algún empleo, el tener una estancia hospitalaria menor a 10 días, es más frecuente el tener Coinfeccion VIH/TB Pulmonar, la variable sexo, 
residencia, ocupación, y estancia hospitalaria, no fueron significativas en el análisis de la interacción de las variables en su conjunto con (OR 1,19; $\mathrm{IC}_{95 \%}$ 0,43-3,27), (OR 1,79; $\mathrm{IC}_{95 \%}$ 0,59-5,41), (OR 1,92; $\mathrm{IC}_{95 \%}$ 0,78-4,69), (OR 2,23; $\mathrm{IC}_{95 \%}$ 0,89-5,58) respectivamente.

\section{Discusión}

El sinergismo entre el BK (bacilo de Koch) y el VIH, junto con la aparición de cepas multirresistentes al tratamiento han llevado a la Organización Mundial de la Salud a declarar a esta enfermedad en situación de emergencia mundial. ${ }^{1}$

La coinfección VIH/Tuberculosis Pulmonar en el hospital José Daniel Rodríguez Maridueña es más frecuente en hombres $47,9 \%$ del total de hombres, frente al $37,5 \%$ del total de mujeres. Predomina la edad de 37 años o más con un $64 \%$ del total de población en este grupo etario; frente al 36,8 \% del total de menores de 37 años. La coinfección es mayor en las personas que viven en Guayaquil con un $45,5 \%$ del total de pacientes de esta provincia, frente a $42,4 \%$ del total de personas que son de otras provincias.

El tener algún tipo de empleo predomina en las personas con coinfección con un 50,5\% del total de los empleados; frente al 35,9\% del total de desempleados, con predominio de primaria en nivel educativo con 56,3 del total de personas con primaria; frente al $32,5 \%$ del total de personas con otros niveles educativos.

Es más probable tener coinfección VIH/TB pulmonar diagnosticada por métodos distintos a la baciloscopía $59 \%$ del total de personas con otros métodos diagnósticos, frente a $36,8 \%$ del total de personas con baciloscopía, es más frecuente la coinfección en personas con $\mathrm{CV}$ menor a $17531854,4 \%$ del total de este grupo, frente al 29,7\% del total de personas con $\mathrm{CV}$ de 175318 o más.

De igual manera la coinfección predomina en personas con CD4 menor a 140, una estancia hospitalaria menor a 10 días, tener VIH y no tomar TARGA con un 53,6\%, 50\%, $100 \%$, del total de este grupo, frente a un CD4 de 140 o más, una estancia hospitalaria de 10 días o más, tener VIH y tomar TARGA con un $36,1 \%, 38,4 \%$ y un $33,3 \%$ del total de pacientes en estos grupos respectivamente.

Las características sociodemográficas dela coinfección VIH/TB Pulmonar coinciden con los datos obtenidos en Cuba, donde se refleja que el mayor porcentaje de los casos (81\%) son hombres, con edades comprendidas entre $27 \mathrm{y}$ 44 años con un $54 \%$ de la epidemia. ${ }^{21}$

En una encuesta realizada en Bangladesh a 52.098 personas mayores de 15 años, en la cual $54 \%$ de los encuestados eran mujeres, se encontró 33 casos nuevos de tuberculosis esputo positivo, de los cuales el $73 \%$ eran hombres, el $61 \%$ vivían en áreas rurales, el mayor porcentaje de casos estaba ubicada en el grupo de edad de 55-64 años, el 45\% de los casos informó no tener ningún tipo de educación formal, y el $42 \%$ se dedicaba a trabajos en el sector no agrícola. ${ }^{22}$

Resultados similares fueron encontrados en un estudio realizados en 74 personas de un hospital público para diagnóstico y tratamiento de enfermedades infecciosas de Brasil, el sexo masculino correspondía al 79,7\%, edad predominante de $30-39$ años $(35,1 \%) .^{13}$

En un estudio realizado en 308 pacientes del Hospital Nacional Dos de Mayo en Lima-Perú el 81,7 \% de los casos estaba representado por el sexo masculino, con una edad media de 35,1 años, el 35,4\% de la población estudiada presento baciloscopía positiva sin ser este método diagnostico predominante. ${ }^{18}$

Un estudio realizado en 356 pacientes con coinfección VIH-Tuberculosis provenientes de dos hospitales de Bogotá, el $61 \%$ tuvieron un recuento de linfocitos T CD4 menor a menores a $200 .^{23}$

Sin embargo, un estudio realizado en 120 casos entre 2004 y 2010 en pacientes con coinfección VIHTuberculosis en el Instituto de Medicina Tropical Pedro Kouri la media de conteo de linfocitos CD4 fue de 193,91, siendo esta coinfección independiente del conteo de CD4. ${ }^{24}$

Los factores asociados a tuberculosis son recuento de linfocitos CD4 menos de 200, la no adherencia al TARGA, elevada carga viral (Beltrán-León et al., 2017).

\section{Conclusiones}

En nuestro estudio el perfil de riesgo para presentar Coinfección tuberculosis pulmonar/ VIH es tener una edad 37 años o más (64\%), educación primaria (56,3\%), confección VIH/TB Pulmonar diagnosticada por métodos distintos a la baciloscopía (59\%), una CV menor a 175318 (54\%), linfocitos TCD4+ menor a 140 células $/ \mathrm{mm}^{3}(53,6 \%)$, el tener VIH y no tomar TARGA $(100 \%)$. Las variables sexo, residencia, Ocupación, y estancia hospitalaria, no fueron significativas en el análisis de la interacción de las variables en su conjunto.

\section{Fuente de Financiamiento}

Este estudio es autofinanciado.

\section{Conflicto de Intereses}

No existen conflictos personales, profesionales, financieroso de otro tipo.

\section{Consentimiento Informado}

Los autores cuentan con el consentimiento informado de los pacientes para la investigación, la publicación del caso y sus imágenes.

\section{Referencias Bibliográficas}

1. Llerena-Rangel C, Arronde-Chappotín A, RomeroCarrazana R, Mora-Guerra R, Turati-Manresa R, Rodríguez-Cruz J. Comportamiento del Mycobacterium tuberculosis en los municipios Lisa, Playa, Marianao y Hospitales de La Habana, Cuba 2012. Revista Peruana De Epidemiología. 2013 dec;17(3):01-05.

2. Nascimento-Belo E, Yamall-Orellana JD, Levino A, Basta PC. Tuberculosis in Amazonian municipalities of the 
Brazil-Colombia-Perú-Venezuela border: epidemiological situation and risk factors associated with treatment de-18. fault. Revista Panamericana de Salud Pública. 2013 nov;34(5):321-329.

3. Blas E, Kurup AS. Equity, Social Determinants and Public Health Programmes. Switzerland: World Health Organization; 2010.

4. Peña-M C, Farga-C V. El difícil camino del control sani- 19 tario de la tuberculosis. Revista chilena de enfermedades respiratorias. $2012 \mathrm{dec} ; 28(4): 311-318$.

5. Ávila MH, Lorenzo YV, Álvarez FEA, Lorenzo FYM, Pérez MC, Berrío YC. Bioseguridad en tuberculosis. MediCiego. 2016;22(3):78-87.

6. Global tuberculosis report 2013. Francia: World Health Organization; 2013.

7. Organización Mundial de la Salud. OMS I Estrategia Alto a la Tuberculosis; 2015.

8. Romero-Sandoval NC, Flores-Carrera OF, Sánchez-Pérez HJ, Sánchez-Pérez I, Mateo MM. Pulmonary tuberculosis in an indigenous community in the mountains of Ecua-2 dor. The International Journal of Tuberculosis and Lung Disease. 2007 may;11(5):550-555.

9. Organización Mundial de la Salud. OMS । Determinantes sociales de la salud; 2014.

10. Organización Panamericana de la Salud. Salud en las 23. Américas. Edición 2012 ed.; 2013.

11. Rouzier VA, Oxlade O, Verduga R, Gresely L, Menzies D. Patient and family costs associated with tuberculosis, including multidrug-resistant tuberculosis, in Ecuador. The 2 International Journal of Tuberculosis and Lung Disease. 2010 oct;14(10):1316-1322.

12. Tanimura T, Jaramillo E, Weil D, Raviglione M, Lönnroth K. Financial burden for tuberculosis patients in low- and middle-income countries: a systematic review. European Respiratory Journal. 2014 jan;43(6):1763-1775.

13. Lemos LdA, Fiuza MLT, Reis RK, Ferrer AC, Gir E, Galvão MTG, et al. Adherence to antiretrovirals in people coinfected with the human immunodeficiency virus and tuberculosis. Revista Latino-Americana de Enfermagem. 2016;24.

14. Organización Mundial de la Salud. OMS I HABLEMOS DE TUBERCULOSIS Y VIH; 2017.

15. Sterling T, Pham P, Chaisson R. HIV Infection-Related Tuberculosis: Clinical Manifestations and Treatment. Clinical Infectious Diseases. 2010 may;50(s3):S223-S230.

16. Dowdy DW, O'Brien MA, Bishai D. Cost-effectiveness of novel diagnostic tools for the diagnosis of tuberculosis. The International Journal of Tuberculosis and Lung Disease. 2008;12(9):1021-1029.

17. Desikan P. Sputum smear microscopy in tuberculosis: Is it still relevant? The Indian Journal of Medical Research.
2013 mar;137(3):442-444.

. Torres del Águila J. CARACTERÍSTICAS CLINICOEPIDEMIOLÓGICAS DE PACIENTES CON COINFECCION DE TUBERCULOSIS Y VIH EN EL HOSPITAL NACIONAL DOS DE MAYO EN EL PERIODO ENERO DEL 2013 A SETIEMBRE DEL 2015. Universidad Ricardo Palma. 2016;

. Procedimientos para la Prevención y control de la Tuberculosis; 2017.

20. Crispín V, Roque M, Salazar ME, Ruiz JR, Ortiz J, Almonacid A, et al. Factores de riesgo para tuberculosis multidrogorresistente en establecimientos de salud urbano marginales 2006-2008. Ciencia e Investigación. 2014 feb;15(1):25-29.

21. de la Paz Bermúdez, Verdasquera Corcho D, Marcelo M, Carlos J, Portela Ramírez D, Pérez J, et al. Manifestaciones clínico radiológicas en pacientes con coinfección tuberculosis pulmonar y VIH/sida. Revista Cubana de Medicina General Integral. 2017 sep;33(3):310-320.

. Hossain S, Quaiyum MA, Zaman K, Banu S, Husain MA, Islam MA, et al. Socio Economic Position in TB Prevalence and Access to Services: Results from a Population Prevalence Survey and a Facility-Based Survey in Bangladesh. PLoS ONE. 2012 sep;7(9).

Beltrán-León M, Pérez-Llanos F, Sánchez L, Parra-López C, Navarrete M, Sánchez R, et al. Prevalencia y factores asociados a tuberculosis y micobacteriosis en pacientes VIH positivos en Bogotá. Biomédica. 2017 jun;38(0).

. de la Paz Bermúdez Tania, Denis VC, Juan Carlos MM, Juan Carlos MM, Daniel PR, Daniel PR, et al. MANIFESTACIONES CLÍNICO RADIOLÓGICAS EN PACIENTES CON COINFECCIÓN TUBERCULOSIS PULMONAR Y VIH/SIDA. IPK. 2004 - 2010. In: 8th Cuban Congress on Microbiology and Parasitology, 5th National Congress on Tropical Medicine and 5th International Symposium on HIV/aids infection in Cuba; 2014.

Recibido: 05 de noviembre de 2019

Aceptado: 16 de diciembre de 2019 